\title{
Harvendusraiete tasuvuse analüüs ja pikaajalise mõju simulatsioonid Järvselja õppe- ja katsemetskonnas
}

\author{
Paavo Kaimre $^{1 *}$, Priit Vellak ${ }^{2}$ ja Meelis Teder $^{1}$
}

Kaimre, P., Vellak, P., Teder, M. 2020. Economic analysis and simulation of the impact of thinning on wood production in Järvselja Training and Experimental Forest Centre. - Forestry Studies | Metsanduslikud Uurimused 72, 54-63, ISSN 1406-9954. Journal homepage: http:/ / mi.emu.ee/forestry.studies

\begin{abstract}
The results of the analysis of profitability and impact of thinning on wood production in Järvselja Training and Experimental Forest Centre are presented in the article. The profitability was assessed on the basis of harvesting income and costs of logging operations in 2015-2017. The impact of thinning on the wood production was assessed using the MOTTI simulation program. Three different scenarios for the management of the stand were compared: 1) stand management in accordance with the Finnish forest management recommendations (Tapio recommendations), 2) management according to the Estonian Forest Management Regulations and 3) stand development without thinning. The results revealed that 61 thinnings out of the 70 were profitable. The average net income from thinning was 344 euros per hectare. Fuel wood accounted for $45 \%$ and pulpwood for $30 \%$ of the harvested timber. Net present value was applied as a criterion to assess the profitability of long-term management scenarios. Considering Tapio's recommendations, the total net present value was 33\% higher and following Estonian forest management rules, it was 23\% higher compared to the simulations without thinning. The results indicated that thinning is economically viable in the long run. In simulations without thinning, timber production is the highest, but the net present value of management is lower compared to simulations with thinning.
\end{abstract}

Key words: thinning, profitability, net present value, MOTTI, scenario.

Authors' addresses: ${ }^{1}$ Chair of Forest Management Planning and Wood Processing Technologies, Institute of Forestry and Rural Engineering, Estonian University of Life Sciences, Kreutzwaldi 5, 51006 Tartu, Estonia; ${ }^{2}$ Milrem Robotics OÜ, Raatuse 20, 51009 Tartu, Estonia; *e-mail: paavo.kaimre@emu.ee

\section{Sissejuhatus}

Harvendusraiete tegemise eesmärk on suurendada puistu tootlikkust, parandada kasvama jäävate puude kvaliteeti ning ennetada puude looduslikku suremust, kasutades looduslikult väljalangevad puud ära puiduna. Kuigi harvendusraiete mõju puistu edasisele arengule on küllaltki palju uuritud, ei ole uuringud andnud alati samasuunalisi tulemusi, mistõttu on autorid esitanud ka erinevaid järeldusi. Harvendusraiete tegemine on uuendusraietega võrreldes keerulisem ja ajamahukam ning raiutav puit enamasti odavam. Eestis on praeguse sajandi algusaastatel olnud harvendus- ja uuendusraiete pindala suhe ligikaudu 1:1,3 ehk uuendusraiete pind-

DOI: $10.2478 /$ fsmu-2020-0005

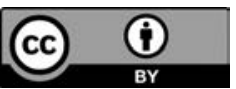

(C) 2020 by the authors. Licensee Estonian University of Life Sciences, Tartu, Estonia. This article is an open access article distributed under the terms and conditions of the Creative Commons Attribution (CC BY) license (http://creativecommons.org/licenses/by/4.0/). 
ala on $30 \%$ suurem. Metsamajanduslikust seisukohast võiks olla olukord vastupidine ja harvendusraiete pindala uuendusraiete pindalast märkimisväärselt suurem. Harvendusraiete soovituslikust väiksema mahu üks põhjus võib olla rahas, st harvendusraietest saadav tulu on uuendusraietega võrreldes väike.

Pikas perspektiivis aga võiks harvendusraiete tulemusena suureneda uuendusraietel varutavate jämesortimentide osakaal ja paraneda puidu kvaliteet, mis tõstab uuendusraietelt saadava puidu hinda. Suurema tüvemahuga puude ülestöötamise kulud on madalamad, sest raietööde efektiivsus on suurem. Nimetatud ökonoomilised tegurid toetavad harvendusraiete tegemist. Üldiselt ollakse seisukohal, et harvendusraietega on võimalik tõsta metsa pikaajalise majandamise tasuvust (Niemistö et al., 2018). Samas on avaldatud uurimusi, mille kohaselt harvendusraie tähendab kulusid (Soucy, 2010).

Harvendusraiete lühi- ja pikaajalise tasuvuse analüüsimiseks on tehtud pikaajalisi katseid, uuritud harvendusraiete mõju üksikpuu tasandil ning loodud erinevaid mudeleid, et ennustada metsakasvatuslike võtete mõju puistu arengule (Mäkinen \& Isomäki, 2004; Renshaw et al., 2009; Teder \& Kaimre, 2015). Katsete ja uuringute abil üritatakse selgitada ning tõestada metsakasvatuslike võtete kasutamise vajalikkust ja majanduslikku potentsiaali. Puidu müügitulu ning ülestöötamise kulusid teades on üksikute harvendusraiete tegemise tasuvust lihtne hinnata. Pikaajalise ökoloogilise ja majandusliku mõju hindamine on märkimisväärselt keerukam, sest arvestada tuleb paljude ajas muutuvate teguritega (Boström, 1982). Ajas muutuvateks ökonoomilisteks teguriteks võib pidada näiteks raha väärtuse, puidu hinna ja ülestöötamise kulude muutusi.

Eestis tehtud harvendusraiete uuringutes on ennekõike keskendutud sellele, kuidas erineva väljaraie aste (raiekraadi) mõjub puistute tootlikkusele (Muiste, 1963; Muiste, 1982). On üldtunnustatud seisukoht, et peale hooldusraiet allesjäävate puude juurdekasv suureneb tänu paranenud valgus- ja toitumistingimustele (Tullus, 1988). Ollakse aga lahkarvamusel, kas allesjäänud puude juurdekasvu suurenemine kompenseerib ja ületab väljaraiutud puude juurdekasvu. Eesti Põllumajanduse Akadeemia metsakasvatuse kateedris tehtud uuringu (Muiste, 1982) kohaselt II ja III boniteedi männikutes tehtud nõrk ja mõõdukas raiekraad ei avalda puistu tootlikkusele olulist positiivset mõju. Tugevama raiekraadiga (>20\% tagavarast) raied võivad aga suurendada puude rinnasdiameetri juurdekasvu kuni 1,5 korda raie-eelsega võrreldes.

Soomes tehtud uuringus (Mäkinen \& Isomäki, 2004) analüüsiti hariliku männi (Pinus sylvestris L.) kasvu ja tootlikkust erinevate raiekraadidega tehtud harvendusraiete korral. Uurimistöö tugines pikaajalisele katsele, mis korraldati Lõuna-Soomes mineraalmuldadel kasvavates puistutes. Uuringus jõuti järeldusele, et harvendusraiete tulemusena vähenes puistus puude looduslik suremus ning puude diameetri juurdekasv suurenes, kui suurendati raiekraadi.

Niemistö et al. (2018) uurimuses analüüsiti keskmise viljakusega kasvukoha männipuistus erinevas vanuses tehtud harvendusraiete tulu ja tulusust ning tõdeti, et esimese harvendusraie tulu 30aastases puistus jäi vahemikku 400-440 eurot ha kohta, hilisem harvendusraie 40aastases puistus aga andis ligikaudu neli korda suurema tulu.

Muiste (1988) artikli „Hooldusraie katsetööd Järvselja metsades" kohaselt on Järvselja õppe- ja katsemetskonnas hooldusraiealast katsetööd tehtud metskonna rajamisest alates. Uuritud on erinevate hooldusraiemeetodite ja harvendamistugevuse mõju hariliku männi, hariliku kuuse (Picea abies Mill.) ja arukase (Betula pendula Roth.) puistute juurdekasvule ja kvaliteedile. Kuna enamikul katsealadel on hooldusraieid ja mõõtmisi tehtud pikka aega, on võimalik teha järeldusi hool- 
dusraievõtete mõju kohta nii puistu tootlikkusele, sanitaarsele seisundile kui ka paljudele takseernäitajatele. Samas aga ei ole Eestis avaldatud uurimistulemusi selle kohta, kuidas mõjutavad harvendusraied puistu majandamise tulusust.

Siinse uuringu eesmärk oli analüüsida harvendusraiete tasuvust Järvselja õppeja katsemetskonna 2015.-2017. aasta andmetel ning selgitada simulatsioonide abil harvendusraiete mõju puistute pikaajalise majandamise tulemustele. Eesmärk oli koostada ülevaade harvendusraietel varutava puidu sortimentatsioonist ning võrrelda erinevate majandamisviiside mõju puistu pikaajalisel majandamisel kujunevale sortimentide proportsioonile.

\section{Materjal ja metoodika}

Uuring koostati Järvselja õppe- ja katsemetskonna puistute põhjal, kus aastatel 2015-2017 tehti harvendusraie. Lühiajalise tasuvuse hindamiseks vajalikud andmed (eraldise nr, tööde maksumus, raiutud puit sortimentide kaupa) saadi tööde vastuvõtmise aktidest. Puistu takseerandmed saadi Järvselja õppe- ja katsemetskonna metsamajanduse infosüsteemi andmebaasist (Järvselja infosüsteem, 2020), mis on internetis leitav aadressil https://jarvselja. emu.ee/.

Lühiajaline tasuvus arvutati eraldiste kaupa sortimentide müügitulu ja metsavarumistööde kulude põhjal, arvutades puhastulu hektari kohta $(€ /$ ha). Valim koosnes 70 eraldisest kogupindalaga 120,4 ha. Kasutati ainult neid eraldisi, mille tööde vastuvõtmise aktidel oli olemas nii raietööde kui ka kokkuveo maksumus või kompleksteenuse (raie + kokkuvedu) maksumus. Puidutulu arvutamisel kasutati Järvselja õppe- ja katsemetskonnas aastatel 2015-2017 müüdud sortimentide keskmisi hindu (Tabel 1).
Tabel 1. Sortimentide keskmine hind $\left(€ / \mathrm{m}^{3}\right)$ vahelaos.

\begin{tabular}{lc}
\hline Sortiment & Hind, $€ / \mathrm{m}^{3}$ \\
\hline Männipalk & 68,30 \\
Männipeenpalk & 39,50 \\
Kuusepalk & 62,30 \\
Kuuselatt & 26,00 \\
Kuusepeenpalk & 38,50 \\
Kasepalk & 35,00 \\
Haavapalk & 37,00 \\
Männipaberipuit & 20,10 \\
Kuusepaberipuit & 20,10 \\
Kasepaberipuit & 23,00 \\
Haavapaberipuit & 22,20 \\
Okaspuu küttepuit & 16.90 \\
Küttepuit & 16,50 \\
\hline
\end{tabular}

Harvendusraiete pikaajalise tasuvuse hindamiseks kasutati MOTTI (2019) simulatsiooniprogrammi. MOTTI on puistu tasemel metsa kasvu simuleerimise programm, mille on välja töötanud kunagise Soome metsauurimisinstituudi METLA spetsialistid Jari Hynyneni juhtimisel, praeguse (alates 01.01.2015) nimega LUKE (soome k Luonnonvarakeskus).

Programmiga modelleeriti eraldise takseerandmete põhjal puistu kasvu kolme erineva stsenaariumi kohaselt ning saadud tulemuste alusel hinnati harvendusraiete pikaajalist tasuvust, arvutades iga stsenaariumi puhasnüüdisväärtuse. Puhasnüüdisväärtuse NPV (1) arvutamisel arvestatakse puistu majandamise tulude ja kuludega, teisendades need diskonteerimismäära abil nüüdisväärtuseks ning leides nende vahe.

$$
N P V=\sum_{0}^{n} \frac{\left(B_{n}-C_{n)}\right.}{(1+i)^{n}}
$$

kus $B_{n}$ on tulud aastal n, $C_{n}$ on kulud aastal n, i on intressimäär. 
Simulatsioonides kasutati 3\% intressimäära. Uuringus arvestati harvendusraiete otseste tulude ja kuludega, kaudsete kuludega (nt metskonna üldkulu, maamaks jms) ei arvestatud. Seetõttu saab saadud tulemuste abil võrrelda erinevate stsenaariumite edukust, aga mitte anda hinnangut puistu majandamise absoluutsele tulususele. Simulatsiooniprogramm MOTTI modelleerib üksikpuu kasvu ja sellega on võimalik hinnata ka metsakasvatuslike võtete mõju puistu majandamisele. Seepärast kasutatakse Soomes seda tarkvara sagedasti metsamajanduslike otsuste langetamisel (Hynynen et al., 2005). Programmis kasutatavatest sisenditest tulenevalt on MOTTI tarkvara kasutamine usaldusväärne vaid Soomes või sarnaste looduslike tingimustega aladel. Mõningate kohandamistega on MOTTI programmi ka varem Eestis kasutatud (Korjus et al., 2011; Teder \& Kaimre, 2015).

Olulisemad puistu kasvu mõjutavad geograafilise asukoha spetsiifilised indeksid on aktiivsete õhutemperatuuride summa, mere indeks ja järve indeks. Järvselja tingimuste jaoks programmi sobivate seadete valimiseks konsulteeriti MOTTI programmi arendajatega. Arvestades Järvseljal valitsevaid olusid, kasutati uurimuse läbiviimisel MOTTI simulatsiooniprogrammis Järvselja asemel Soome Karjalohja piirkonda (nn mere indeks 0,0; järve indeks 18,5 ja temperatuuride summa 1333). Eesti ja Soome kasvukohatüübid erinevad üksteisest. Uurimuses kasutati peamiste Eesti metsakasvukohatüüpide teisendamiseks andmeid teadusartiklist "Evaluation of the basal area growth models in the Finnish stand simulator MOTTI with data from the Estonian network of permanent forest growth plots" (Lilleleht et al., 2011), kus Eesti peamisi kasvukohatüüpe on võrreldud MOTTI programmis kasutatud viljakusklassidega (nt naadi kasvukohatüüp on 1. viljakusklass).
Simulatsioonides kasutati hariliku kuuse, arukase ja hariliku männi peapuuliigiga eraldisi, mille kohta tehti kolm erinevat simulatsiooni. Kuna MOTTI programmi vaikeseaded võimaldavad sortimentatsiooni ja materjali hindu muuta vaid kolmel eelmainitud puuliigil, siis jäid 19 eraldise andmed simulatsioonides kasutamata. Simulatsiooni jaoks sisestati puistu harvendusraie-eelsed puistuelemendi inventeerimisandmed: puuliik, rinne, tekkeviis, vanus, kõrgus, diameeter ja rinnaspindala. Näitajaid ei modifitseeritud Soome arvutusreeglite kohaselt. Olemasolevat puistu kahjustusastet ja harvendusraiete võimalikku mõju selle muutusele ning uute kahjustuste tekkimisele simulatsioonides ei arvestata. Simulatsiooni tulemusena saadakse puistu majandamise tulude ja kulude puhasnüüdisväärtus eurodes.

Simulatsioonis 1 (nn Tapio variant) on kasutatud Soome metsamajandusorganisatsiooni Tapio soovitusi, modelleerides puistu majandamist inventeerimise hetkest (st olemasolevaid takseerandmeid kasutades) kuni uuendusraieni. See on automaatne simulatsioon, mille käigus MOTTI programm kavandas nii erinevad harvendusraied kui ka lageraie. Simulatsioonis 2 (harvendusraietega variant) toimus puistu majandamine kuni lageraieni (kaasa arvatud), lähtudes kehtivast metsaseadusest ja metsa majandamise eeskirjast. Simulatsioonis 3 harvendusraieid ei kavandatud, puistu kasvu modelleeriti olemasolevast seisundist kuni lageraieni, mis toimus samal ajal kui simulatsioonis 2 .

Esimeses simulatsioonis ühtegi muutujat peale puistu inventeerimisandmete ja sortimenteerimisparameetrite (Tabel 2) ei sisestatud. Programm tegi simulatsiooni ise. Peenpalkide minimaalseks pikkuseks määrati 3,5 meetrit ja paberipuidul 3,0 meetrit. 
Tabel 2. Simulatsioonis kasutatud sortimentide parameetrid.

\begin{tabular}{lccc}
\hline Puuliik & $\begin{array}{c}\text { Palkide minimaalne } \\
\text { läbimõõt, } \mathrm{cm}\end{array}$ & $\begin{array}{c}\text { Peenpalkide minimaalne } \\
\text { läbimõõt, } \mathrm{cm}\end{array}$ & $\begin{array}{c}\text { Paberipuidu minimaalne } \\
\text { läbimõõt, } \mathrm{cm}\end{array}$ \\
\hline Harilik mänd & 18 & 12 & 6 \\
Harilik kuusk & 18 & 12 & 7 \\
Arukask & 16 & 16 & 6 \\
\hline
\end{tabular}

Tabel 3. Sortimentide kännuraha $\left(€ / \mathrm{m}^{3}\right)$ harvendus- ja lageraietel.

\begin{tabular}{lcc}
\hline Sortiment & $\begin{array}{c}\text { Lageraie, } \\
€ / \mathrm{m}^{3}\end{array}$ & $\begin{array}{c}\text { Harvendusraie, } \\
€ / \mathrm{m}^{3}\end{array}$ \\
\hline Männipalk & 61,96 & 57,45 \\
Männipeenpalk & 45,23 & 40,72 \\
Kuusepalk & 59,90 & 55,39 \\
Kuusepeenpalk & 45,32 & 40,81 \\
Kasepakk & 100,57 & 96,06 \\
Kasepalk & 49,32 & 44,81 \\
Haavapalk & 23,11 & 18,60 \\
Männipaberipuit & 14,58 & 10,07 \\
Kuusepaberipuit & 14,23 & 9,72 \\
Kasepaberipuit & 13,96 & 9,45 \\
Haavapaberipuit & 6,57 & 2,06 \\
Küttepuit & 8,33 & 3,82 \\
\hline
\end{tabular}

Teises simulatsioonis tehti harvendusraie metskonnas tegelikult raiutud puistu vanuses. Vajadusel tehti ka teine harvendusraie, mille juures lähtuti puistu vanusest ja jälgiti programmi arvutatavat suremus- joont. Kõik raied modelleeriti alameetodil metsa majandamise eeskirja alusel. Harvendusraiete modelleerimiseks sisestati programmi harvendusraiejärgne minimaalne lubatud rinnaspindala.

Teises ja kolmandas simulatsioonis kasutati lageraie vanustena metsa majandamise eeskirjas (2006) kehtestatud raiet lubavaid vanuseid, mida rakendati eraldise takseerkirjelduses märgitud enamuspuuliigi järgi.

Tasuvusarvutuste tegemisel kasutati 2017. aasta puiduhindade ja ülestöötamise kulude (Sirgmets \& Kaimre, 2018) abil arvutatud sortimentide kännuraha (Tabel 3). Kuludena arvestati metsavarumise kompleksteenuse maksumust, mis lageraiel oli $12,37 € / \mathrm{m}^{3}$ ja harvendusraietel $16,88 € / \mathrm{m}^{3}$.

\section{Tulemused}

Analüüsitud harvendusraiete keskmine puhastulu hektari kohta oli $344 € /$ ha (Tabel 4). Enamik (kuuskümmend üks seitsmekümnest ehk $87 \%$ ) raietest andis puhastulu. Keskmine väljaraie oli 41,2 tm/ha.

Tabel 4. Analüüsitud harvendusraiete koondandmed.

\begin{tabular}{lcccccc}
\hline Aasta & $\begin{array}{c}\text { Valimi } \\
\text { maht }\end{array}$ & $\begin{array}{c}\text { Pindala, } \\
\text { ha }\end{array}$ & $\begin{array}{c}\text { Raiemaht, } \\
\text { tm }\end{array}$ & $\begin{array}{c}\text { Keskmine väljaraie, } \\
\text { tm/ha }\end{array}$ & $\begin{array}{c}\text { Puhastulu, } \\
€\end{array}$ & $\begin{array}{c}\text { Keskmine puhastulu, } \\
\text { /ha }\end{array}$ \\
\hline 2015 & 22 & 26,3 & 1140 & 43,3 & 11098 & 422 \\
2016 & 24 & 48,4 & 1755 & 36,3 & 13167 & 272 \\
2017 & 24 & 45,7 & 2120 & 46,4 & 17144 & 375 \\
$2015-2017$ & 70 & 120,4 & 4966 & 41,2 & 41409 & 344 \\
\hline
\end{tabular}


Kõige kahjumlikum raielank andis 299 $€ /$ ha kahjumit, suurima puhastuluga harvendusraielt saadi $2206 € /$ ha.

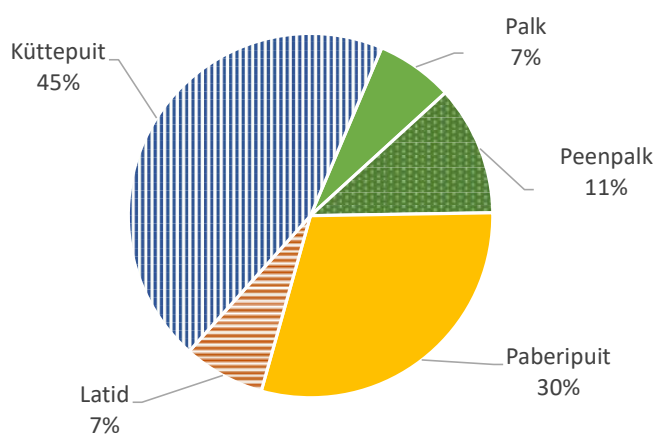

Joonis 1. Harvendusraietelt saadud puidu jaotus sortimentideks.
Raiete tasuvus sõltub saadud sortimentidest, mis omakorda sõltub puistu vanusest ja tervislikust seisukorrast. Alameetodil tehtud harvendusraiete käigus raiutakse kasvus alla jäänud puude tüvesid või haigestunud puid. Kuna Järvselja õppeja katsemetskonnas tehti harvendusraied alameetodil, siis saadi peamiselt küttepuitu (45\% kogu puidu mahust). Rohkem kui kolmandiku puidust moodustasid paberipuit ja latid (Joonis 1).

Simulatsioonitulemuste kõrvutamine näitab, et puistute tootlikkus (puidu kogus) oli raieteta simulatsioonides suurem, kuid harvendusraietega simulatsioonides saadi kõrgema hinnaga sortimente rohkem, mis andis suurema puhasnüüdisväärtuse, võrreldes harvendusraieteta simulatsioonidega (Tabel 5).

Tabel 5. Erinevate stsenaariumide korral tekkivate sortimentide kogus (tm) ja nende keskmine osakaal (\%) puidu koguses.

\begin{tabular}{lcccccc}
\hline \multirow{2}{*}{ Sortiment } & \multicolumn{5}{c}{ Stsenaarium } \\
\cline { 2 - 7 } & \multicolumn{2}{c}{ Tapio } & \multicolumn{5}{c}{ Harvendusraietega } & \multicolumn{2}{c}{ Harvendusraieteta } \\
\cline { 2 - 7 } & tm & $\%$ & tm & $\%$ & tm & $\%$ \\
\hline Palk & 11163,6 & 47,52 & 18621,8 & 57,75 & 16338,9 & 50,51 \\
Peenpalk & 1926,7 & 8,20 & 2194,3 & 6,80 & 2030,4 & 6,28 \\
Paberipuit & 9169,0 & 39,03 & 10049,7 & 31,17 & 6543,7 & 20,23 \\
Jäätmed & 689,4 & 2,93 & 682,7 & 2,12 & 233,1 & 0,72 \\
Surnud puit & 544,6 & 2,32 & 697,6 & 2,16 & 7200,9 & 22,26 \\
Kokku & 23493,3 & 100,00 & 32246,1 & 100,00 & 32347,0 & 100,00 \\
\hline
\end{tabular}

Tabelis olevad arvud kirjeldavad väga hästi harvendusraiete majanduslikku otstarbekust, s.o erineva hinnaga sortimentide osakaalu muutust ja puidu kasutamist enne, kui puude suremise tõttu toimub nn looduslik väljalangemine ja puidu kõdunemine. Tapio ja harvendusraietega simulatsioonides oli surnud puidu osa vastavalt $2,3 \%$ ja 2,2\%, harvendusraieteta simulatsioonides tekkis surnud puitu $22,3 \%$.

Pikaajalise tasuvuse hindamiseks oli valimi põhjal võimalik arvutada 51 puistu simulatsioonide puhasnüüdisväärtus (Ta- bel 6). Arvutusi ei tehtud sanglepa (Alnus glutinosa (L.) Gaertn.) ja hariliku haava ( $P_{0-}$ pulus tremula L.) puistute kohta, sest MOTTI programmis ei ole nende puuliikide jaoks mudeleid.

Kõigi kolme aasta simulatsioonide summeeritud puhasnüüdisväärtus on Tapio variandil 33\% ja harvendusraietega simulatsioonil 23\% suurem kui harvendusraieteta stsenaariumil. Kuna nn Tapio simulatsiooni korral on puistu majandamine kõige intensiivsem (kõige rohkem harvendusraieid) ja harvendusraieteta si- 


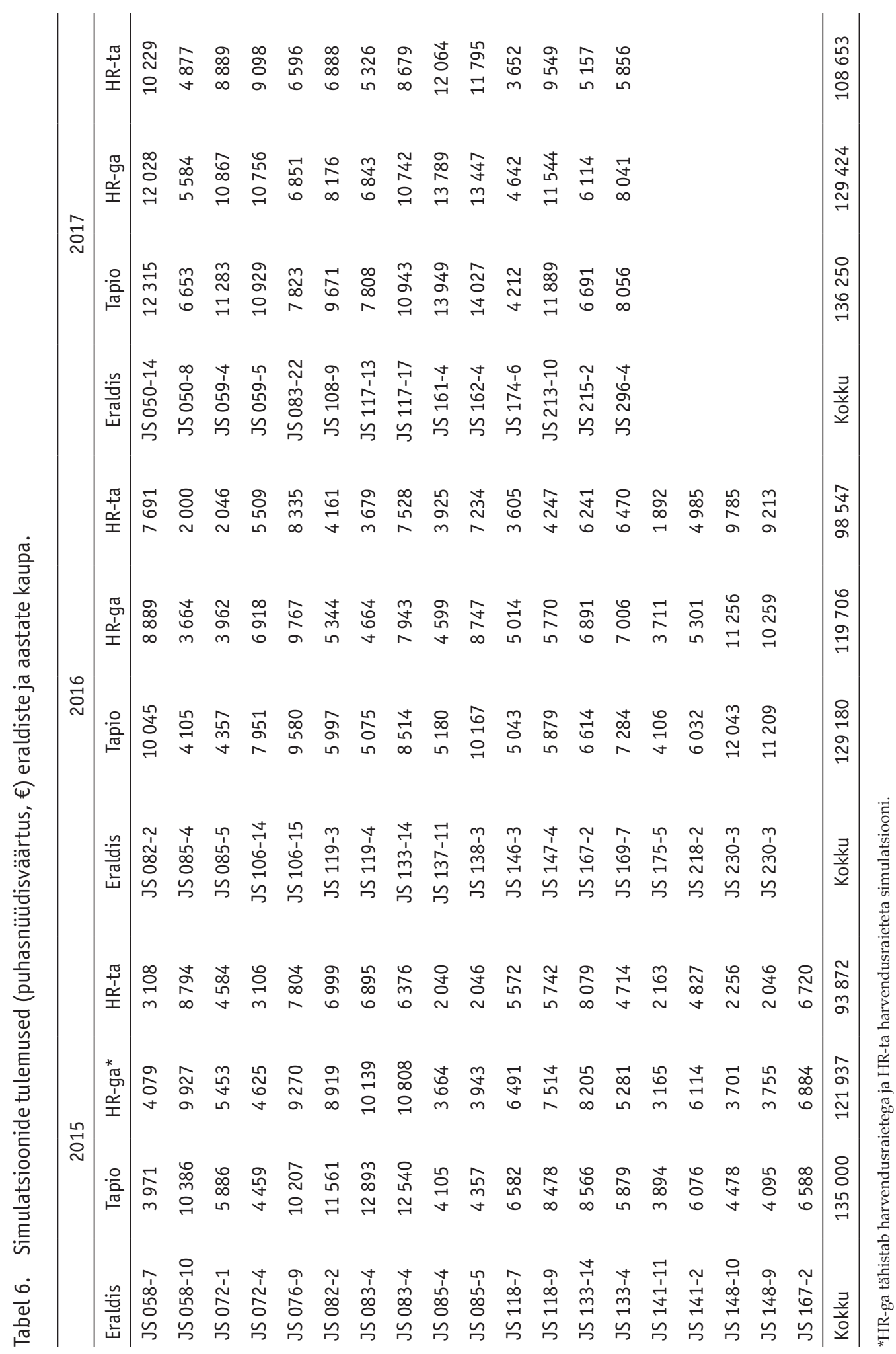


mulatsiooni korral looduslikku arengusse mittesekkuv, saab arvutuste põhjal teha järelduse, et mõõdukalt intensiivse majandamise korral saavutatakse suurem puhasnüüdisväärtus kui majandamata jätmisel. Tulemus viitab harvendusraiete kasutamise majanduslikule otstarbekusele puistute pikaajalisel majandamisel.

\section{Arutelu ja järeldused}

Järvselja õppe- ja katsemetskonna harvendusraiete analüüsi tulemused näitasid harvendusraiete majanduslikku põhjendatust nii lühikeses kui pikas perspektiivis. Aastatel 2015-2017 tehtud enamik harvendusraietest olid kasumlikud, st puidutulu ületas raietööde kulusid. Iga raielangi tulemust mõjutavad erinevad tegurid, lisaks enamuspuuliigile ja sortimentidele ka nt kokkuveokaugus. Mitme kahjumit andnud eraldise puhul oli veokaugus keskmisest pikem, isegi kuni 1200 meetrit. Erinevate tegurite (nt tüvemaht, veokaugus, väljaraie \%) mõju harvendusraie kasumlikkusele vajab eraldi uuringut ja usaldusväärsete tulemuste saamiseks suuremat hulka algandmeid. Järvseljal tehtud harvendusraiete kasumlikkus võib tuleneda ka metskonnas tehtud nn eelvalikust. Raiet kavandades juba arvestatakse sellega, et puidutulu ületaks metsavarumiskulusid. Keskmine puhastulu $344 € /$ ha kohta jääb samasse suurusjärku Soomes tehtavate esimese harvendusraie tuludega (Niemistö et al., 2018). Kuna Soomes on paberipuidu hinnad kõrgemad kui Eestis, on sealne harvendusraietelt saadav tulu arusaadavalt suurem kui Eestis.

Harvendusraietega varutud puidu sortimentatsioon peegeldab raiete eesmärgipärasust - suurima osa moodustab küttepuit. Tulemus viitab sellele, et võib-olla on harvendusraie tegemisega isegi veidi hiljaks jäädud. Harvendusraiete väga oluline majanduslik kasu tuleneb sellest, et looduslikult surevad puud kasutatakse ära tarbepuiduna. Simulatsioonide tulemused kinnitasid varasemates töödes (Nilsson et al., 2010; Teder \& Kaimre, 2015) esitatud seisukohta, et hooldusraieid tehes väheneb puude looduslik suremus. Õigemini küll ennetatakse harvendusraietega puude suremist ja madala hinnaga küttepuidu teket, kasutades ära puistu puidutootmise potentsiaali paberipuiduna.

Järvseljal tehtud harvendusraiete keskmine väljaraie oli 41,2 tm/ha, mis on märkimisväärselt väiksem Riigimetsa Majandamise Keskuse tegelike raieandmete põhjal arvutatud harvendusraiete keskmisest väljaraiest, mis 2017. a oli $72 \mathrm{tm} /$ ha (Keskkonnaagentuur, 2020). Artikli autorid ei analüüsinud puistut kirjeldavate näitajate mõju raiutava puidu kogusele, mistõttu võib vaid oletada mainitud erinevuse põhjusi: nt puistute vanus, tagavara, keskmine tüvemaht. Raiutava puidu koguse erinevuse selgitamiseks tuleks võrrelda uuritud harvendusraieobjekte mujal Eestis tehtud raietega. Põhjus võib olla ka teadlikult valitud väiksemas raieintensiivsuses. Järvselja õppe- ja katsemetskonnas 2017. aastal tehtud harvendusraietel varutud puidu kogus oli keskmiselt 20,9\% puistu tagavarast.

Palkide suurim osakaal harvendusraietega stsenaariumis tuleneb tõenäoliselt pikemast puistu kasvatamise ajast, võrreldes Tapio stsenaariumiga, ning harvendusraiete mõjust diameetri kasvule, võrreldes harvendusraieteta stsenaariumiga. Diameetri täiendav kasv ja saadavate sortimentide parem hind annab harvendusraieid tehes suurema puhasnüüdisväärtuse kui majandamine ainult lageraiega. Puistute majandamise mudelid tulekski kujundada sellisena, et harvendus- ja uuendusraied tervikuna annaksid finantsmajanduslikult parima tulemuse.

Tänusõnad. Uuringu koostajad tänavad Soome metsateadlasi prof Jari Hynyneni ja dr Hannu Salmineni MOTTI tarkvara puudutavate nõuannete eest ning Järvselja õppe- ja katsemetskonna metsaülem Tanel Piiri abi eest harvendusraiete algandme- 
te hankimisel. Siiras tänu retsensentidele käsikirja kohta tehtud kasulike märkuste ja soovituste eest.

\section{Kasutatud kirjandus}

Boström, C. 1982. Profitability of thinning: shortand long-term considerations. - New Zealand Journal of Forestry Science, 12, 364-379.

Hynynen, J., Ahtikoski, A., Siitonen, J., Sievänen, R., Liski, J. 2005. Applying the MOTTI simulator to analyse the effects of alternative management schedules on timber and non-timber production. - Forest Ecology and Management, 207, 5-18. https://doi. org/10.1016/j.foreco.2004.10.015.

Järvselja infosüsteem. 2020. Järvselja Forest Management Information System. (Järvselja Metsamajandamise Infosüsteem). [WWW document]. - URL https://jarvselja.emu.ee/. [Accessed 6 January 2020]. (In Estonian).

Keskkonnaagentuur. 2020. Yearbook Forest 2018. (Aastaraamat Mets 2018). Tallinn, Estonian Environment Agency. 297 pp. (In Estonian).

Korjus, H., Põllumäe, P., Rool, S. 2011. Profitability analysis of short rotations in Scots pine, Norway spruce and silver birch stands. - Forestry Studies / Metsanduslikud Uurimused, 54, 28-36.

Lilleleht, A., Sims, A., Kiviste, A., Hynynen, J., Lehtonen, M. 2011. Evaluation of the basal area growth models in the Finnish stand simulator MOTTI with data from the Estonian network of permanent forest growth plots. - Forestry Studies / Metsanduslikud Uurimused, 55, 8097. https:/ / doi.org/10.2478/v10132-011-0104-8.

Metsa majandamise eeskiri. 2006. Forest management act. (Metsa majandamise eeskiri). - RT I, 15.12.2017, 17. (In Estonian).

MOTTI. 2019. Motti User's guide: version 3.2.1. [WWW document]. - URL www.metla. fi/metinfo/motti/pdf/manual-3-2-1.pdf. [Accessed 21 May 2019].

Muiste, L. 1963. Improvement cuttings in pine forests. (Hooldusraietest männikutes). Compilation of Research Papers of the Estonian Agricultural Academy: Forest Management Studies. (Eesti Põllumajanduse Akadeemia teaduslike tööde kogumik: Metsamajandusalased tööd). Tartu, Estonian Agricultural Academy, 118-129. (In Estonian).

Muiste, L. 1982. Impact of improvement cuttings on forest increment in Soviet Estonia. (Hooldusraiete mõju metsade juurdekasvule Eesti NSV-s). - Research Report. (Metsakasvatuse kateedri lepingulise teadusliku töö nr. 258 aruanne 1980...1981. aasta kohta). Tartu, Estonian Agricultural Academy. 46 pp. (In Estonian).
Muiste, L. 1988. Experimental improvement cuttings in the forests of Järvselja. (Hooldusraie katsetööd Järvselja metsades). - Forest Management 1985. (Metsamajandus 1985). Tallinn, Valgus, 69-87. (In Estonian).

Mäkinen, H., Isomäki, A. 2004. Thinning intensity and growth of Scots pine stands in Finland. - Forest Ecology and Management, 201(2), 311-325.

Niemistö, P., Kilpeläinen, H., Poutiainen, E. 2018. Effect of first thinning type and age on growth, stem quality and financial performance of a Scots pine stand in Finland. - Silva Fennica, 52, 7816. https:/ / doi.org/10.14214/sf.7816.

Nilsson, U., Agestam, E., Ekö, P.-M., Elfving, B., Fahlvik, N., Johansson, U., Karlsson, K., Lundmark, T., Wallentin, C. 2010. Thinning of Scots pine and Norway spruce monocultures in Sweden: Effects of different thinning programmes on stand level gross- and net stem volume production. - Studia Forestalia Suecia, Report. Umeå, Swedish University of Agricultural Sciences, Faculty of Forest Sciences. 47 pp.

Renshaw, E., Comas, C., Mateu, J. 2009. Analysis of forest thinning strategies through the development of space-time growth-interaction simulation models. - Stochastic Environmental Research and Risk Assessment, 23(3), 275-288. https:/ / doi.org/10.1007/s00477-008-0214-x.

Sirgmets, R., Kaimre, P. 2018. Formation of standard unit prices of subsidies paid in the framework of action no. 08 ,Investments in forest area development and improvement of the viability of forests" of the Estonian rural development policy for 2014-2020. (Eesti maaelu arengukava 2014-2020 meetme 08 "Investeeringud metsaala arengusse ja metsade elujõulisuse arendamisse" raames makstavate toetuste standardsete ühikuhindade kujunemine). Tartu, Estonian University of Life Sciences, Institute of Forestry and Rural Engineering. 17 pp. (In Estonian).

Soucy, M. 2010. Importance of wood value in the thinning profitability problem. - A Thesis Submitted in Partial Fulfillment of the Requirements for the Degree of Doctor of Philosophy in the Graduate Academic Unit of Forestry and Environmental Management. Fredericton, The University of New Brunswick. 240 pp.

Teder, M., Kaimre, P. 2015. Economic analysis of thinnings. (Harvendusraiete ökonoomiline analüüs). - Research Report. Tartu, Estonian University of Life Sciences. 34 pp. (In Estonian).

Tullus, H. 1988. The effect of thinning on stand growth. (Harvendus- ja põimendusraiete mõju puistute kasvule). - Forest Management. (Metsamajandus). Tallinn, Valgus, 60-68. (In Estonian). 


\title{
Economic analysis and simulation of the impact of thinning on wood production in Järvselja Training and Experimental Forest Centre
}

\author{
Paavo Kaimre, Priit Vellak and Meelis Teder
}

\section{Summary}

To analyze the profitability of thinning, long-term experiments have been conducted, the effects of thinning at a single-tree level have been investigated, and various models have been developed to predict the impact of silvicultural practices on stand development. The aim of this study was to analyze the profitability of thinning in a time period from 2015 to 2017 in Järvselja Training and Experimental Centre and to simulate the impact of thinning on the financial performance of long-term forest management. In addition, the aim was to compile an overview of the timber assortments removed in thinning and to compare the effect of different management scenarios on the proportion of assortments formed during the long-term stand management.

The profitability was calculated for each stand on the basis of timber sales revenue and costs of logging operations as a net income per hectare. The sample consisted of 70 stands with a total area of 120.4 ha. The MOTTI simulation program was used to evaluate the impact of thinning on the profitability of forest management. Three different scenarios of stand management were compared: stand management in accordance with Finnish forest management recommendations (Tapio recommendations), management according to the Estonian Forest Management Regulations and stand development without thinning.

The profitability of thinning depends on the assortments removed, which, in turn, depends on the age and health of the trees. As thinning in Järvselja Experimental and Training Centre was done from below, $45 \%$ of the harvested timber was firewood. More than a third of the wood volume were pulpwood and rods. The average net income per hectare of the analyzed thinning was 344 euros. Most (sixty-one out of seventy, or $87 \%$ ) fellings yielded a net income. The average harvested volume was $41.2 \mathrm{~m}^{3}$ per hectare.

The cumulative net present value of the simulations was 33\% higher for the Tapio variant and $23 \%$ for the thinning simulation compared to the no-thinning scenario. With moderately intensive management, a higher net present value is achieved. The results indicate economic feasibility of thinnings for long-term forest management. The results of the simulations corroborated the results of previous studies that the natural mortality of trees is reduced when performing thinning. Thinning utilizes the timber production potential of a stand via the procurement of pulpwood. Due to thinning the additional stem diameter increases and better prices for harvested timber give a higher net present value, compared to a no-thinning management scenario with a final felling only. 